\title{
Eltrombopag treatment of patients with secondary immune thrombocytopenia: retrospective EHR analysis
}

\author{
Pallavi Patwardhan ${ }^{1} \cdot$ Adrienne Landsteiner $^{2} \cdot$ Lincy S. Lal $^{3} \cdot$ Lincy Geevarghese $^{1} \cdot$ Lisa $_{\text {Le }}{ }^{2} \cdot$ Savita Nandal $^{1}$. \\ Adam Cuker ${ }^{4}$
}

Received: 24 February 2021 / Accepted: 29 July 2021 / Published online: 10 September 2021

(c) The Author(s) 2021

\begin{abstract}
Immune thrombocytopenia (ITP) may occur in isolation (primary) or in association with a predisposing condition (secondary ITP [sITP]). Eltrombopag is a well-studied treatment for primary ITP, but evidence is scarce for sITP. We evaluated real-world use of eltrombopag for sITP using electronic health records. Eligible patients had diagnoses of ITP and a qualifying predisposing condition, and eltrombopag treatment. We described patient characteristics, treatment patterns, platelet counts, and thrombotic and bleeding events. We identified 242 eligible patients; the most common predisposing conditions were hepatitis $\mathrm{C}$ and systemic lupus erythematosus. Average duration of eltrombopag treatment was 6.1 months. Most (81.4\%) patients achieved a platelet count $\geq 30,000 / \mu \mathrm{L}$ at a mean of 0.70 months, $70.2 \%$ reached $\geq 50,000 / \mu \mathrm{L}$ at a mean of 0.95 months, and $47.1 \%$ achieved a complete response of $>100,000 / \mu \mathrm{L}$ at a mean of 1.43 months after eltrombopag initiation. At eltrombopag discontinuation, 105 patients (43\%) experienced a treatment-free period for a mean 3.3 months. Bleeding events occurred with similar frequency before and during eltrombopag treatment whereas thrombotic events were less frequent during eltrombopag treatment. Our results suggest similar rates of platelet response with eltrombopag in patients with sITP as compared with primary ITP. In addition, a treatment-free period is possible for a substantial minority of patients.
\end{abstract}

Keywords Secondary immune thrombocytopenia · Eltrombopag $\cdot$ Platelet response $\cdot$ Electronic health records · Retrospective study

\section{Introduction}

Immune thrombocytopenia (ITP) is an acquired condition resulting from immune-mediated impairment of platelet production and/or peripheral platelet destruction. [1] ITP may occur in isolation (primary ITP), or in association with a predisposing condition (secondary ITP [sITP]). It has been

Lincy S. Lal

lincy.lal@uth.tmc.edu

Pallavi Patwardhan

pallavi.patwardhan@gmail.com

Adrienne Landsteiner

ada.landsteiner@gmail.com

Lincy Geevarghese

lincy.geevarghese@novartis.com

Lisa Le

lisa.le@optum.com

Savita Nandal

savita.nandal@novartis.com estimated that approximately $20 \%$ of cases of ITP in adults are sITP. [2, 3] Conditions associated with sITP include broader autoimmune diseases such as systemic lupus erythematosus (SLE), [4] Evans syndrome, and antiphospholipid syndrome (APS); immune deficiencies such as common variable immune deficiency (CVID), [5] selective IgA deficiency, and autoimmune lymphoproliferative syndrome [6];

\footnotetext{
Adam Cuker

adam.cuker@pennmedicine.upenn.edu

1 Novartis Pharmaceuticals Corporation, East Hanover, NJ, USA

2 Optum Health Economics and Outcomes Research, 11000 Optum Circle, Eden Prairie, MN 55344, USA

3 University of Texas School of Public Health, Houston, TX, USA

4 Department of Medicine and Department of Pathology \& Laboratory Medicine, Perelman School of Medicine, University of Pennsylvania, Philadelphia, PA, USA
} 
infection with hepatitis $\mathrm{C},[7,8]$ human immunodeficiency virus, [9] and Helicobacter pylori [10]; and certain lymphoproliferative disorders such as chronic lymphocytic leukemia (CLL) [11] and small lymphocytic lymphoma (SLL).

The thrombopoietin receptor agonist (TPO-RA), eltrombopag, is an option for second-line treatment of primary ITP. [12] Its use was approved by the United States Food and Drug Administration (US FDA) in 2008, based on clinical trials comparing eltrombopag with placebo among patients with primary ITP. However, patients with secondary ITP were excluded. [13-15].

Eltrombopag has been used successfully in sITP associated with CLL, SLE, Evans syndrome, HIV, and APS. [16] However, to date, the accumulated evidence represents a small number of patients, primarily case reports. In the current study, we evaluated the real-world use of eltrombopag among patients with ITP secondary to a variety of predisposing conditions using an electronic health records (EHR) dataset. We aimed to describe patients with sITP treated with eltrombopag, evaluate clinical outcomes including platelet counts and thrombotic or bleeding events, and characterize treatment patterns including duration of eltrombopag therapy and attainment of a treatment-free period.

\section{Methods}

\section{Data source}

This study was performed using EHR data obtained from the Optum Clinical Database, which aggregates clinical records from a network of more than 140,000 providers at more than 700 hospitals and 7000 clinics and contains data for more than 64 million unique US patients. A proprietary deterministic matching technology allows linkage among different sources to cover the full spectrum of health care. The data are structured in a relational database comprising tables constructed from different parts of EHRs, different electronic medical records systems (e.g., prescribed medications, diagnosis codes, health care encounters, and laboratory test results), and select components of physician notes.

\section{Patient selection criteria}

Eligible patients were required to have a diagnosis of ITP as confirmed by ICD-9/10 code (Appendix Table A1); a qualifying predisposing condition (SLE, Evans syndrome, antiphospholipid syndrome, CVID, selective IgA deficiency, autoimmune lymphoproliferative syndrome, HIV, HCV, CLL, and SLL) as indicated by ICD-9/10 code (Appendix Table A2); and treatment with eltrombopag. In addition, evidence of clinical activity in the EHR database was required for at least 3 months prior to and 6 months after the identified sITP diagnosis. Patients were excluded for pregnancy, clinical trial enrollment, or eltrombopag use in the 3-month baseline period. We also excluded cases of ITP and Helicobacter pylori because, whereas evidence of an association is apparent in other parts of the world including Italy and Japan, there is not a clear association between these entities in the USA. [10].

\section{Study design}

The entire period for this descriptive retrospective study encompassed 11 years between 01 January 2008 and 31 December 2018. For patients included in the study, observation started with diagnosis of a qualifying predisposing condition known to be associated with ITP. Following diagnosis of a qualifying condition, the first date on which an ITP

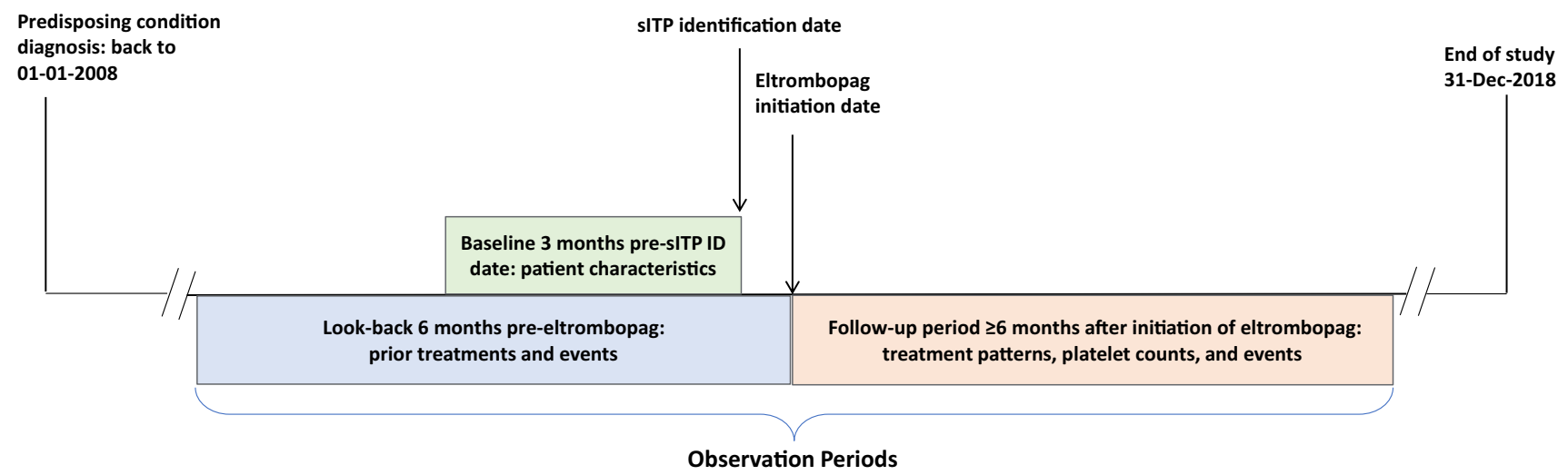

Fig. 1 Study design and time periods designated for baseline and follow-up data collection. sITP, secondary immune thrombocytopenia. The sITP identification date is the first date on which an ITP diagnosis code was observed after the qualifying predisposing condition was diagnosed. The earliest ITP diagnosis may have occurred before the qualifying predisposing condition diagnosis, but inclusion criteria required both diagnoses present prior to the eltrombopag treatment period observed for this study 
diagnosis code was listed set the sITP identification date. All subjects were observed for a 3-month baseline period immediately before the sITP identification date for patient characteristics (Fig. 1).

The date on which eltrombopag treatment was initiated was set as the eltrombopag initiation date. Patients were observed for a 6-month look-back period prior to this date to identify previous treatment(s) and bleeding or thrombotic events and for at least 6 months after initiation of eltrombopag for observation of treatment patterns and outcomes. These time periods were chosen as optimal for the type of data needed. Treatment patterns were observed until disenrollment from the database, death, or end of study on 31 December 2018.

\section{Study variables}

\section{Patient characteristics}

The following patient characteristics were collected in the baseline period: age, race/ethnicity, predisposing condition, health insurance type (commercial, Medicare, Medicaid, uninsured, other/unknown), and Quan-Charlson comorbidity score. [17] Length of time for which patients had continuous activity in the EHR database, reaching back to the start date of the study, was also recorded.

\section{Treatment patterns}

Pharmacy and medical orders were accessed to observe use of eltrombopag as monotherapy or in combination with other ITP treatments such as rituximab, romiplostim, splenectomy, corticosteroids, intravenous immune globulin (IVIG), anti-D, or fostamatinib. The eltrombopag treatment period began on the date of the first order for eltrombopag after the diagnosis of sITP. The observed eltrombopag treatment period ended by several criteria: death; discontinuation (90 days of no eltrombopag orders); start or addition of a new ITP therapy; end of the study period; or absence of EHR activity. As long as the patient remained alive and active in the EHR database, treatment patterns were observed until the end of the study period.

The use of systemic corticosteroids, IVIG, or anti-D was captured and described as rescue medication when it occurred after the start of the eltrombopag treatment period. The proportion of patients who initiated a second line of therapy (eltrombopag, rituximab, romiplostim, or splenectomy) following the observed eltrombopag treatment period was calculated. The time (months) between the end of the eltrombopag treatment period and the start of a subsequent treatment (eltrombopag restarted $>90$ days after the original eltrombopag treatment period or initiation of another second-line treatment), as well as the length of each, were captured. The span of time after eltrombopag treatment ended, during which no rescue medication nor other ITP regimen was ordered, was reported as "treatment-free."

\section{Outcomes}

Platelet counts All available platelet counts for the baseline period and follow-up period were captured. Mean platelet counts were calculated for a period within 14 days prior to initiation of eltrombopag therapy. From the initiation date of eltrombopag, mean platelet counts were calculated for the entire eltrombopag treatment period, as well as for a 6-month span. In addition, the proportion of patients reaching prespecified platelet count response levels and the time to those responses were noted. A first-level response was defined as $\geq 30,000 / \mu \mathrm{L}$; a second-level response as $\geq 50,000$ / $\mu \mathrm{L} ;$ and a complete response as $\geq 100,000 / \mu \mathrm{L}$.

Thromboembolic events During the follow-up period, arterial and venous thromboembolic events (thrombotic stroke, transient ischemic attack, myocardial infarction, deep vein thrombosis, and pulmonary embolism), based on ICD codes (Appendix Table A3), were captured.

Bleeding events Bleeding and hemorrhagic events were also identified by ICD codes (Appendix Table A4).

\section{Statistical analysis}

Analysis was primarily descriptive, reporting proportions and mean (standard deviation [SD]) and median (minimum, maximum) as appropriate for patient characteristics, treatment patterns, and platelet counts. Chi-square and Fisher's exact tests were used to compare the incidence of bleeding events and thrombotic events prior to and after the initiation of eltrombopag treatment. Because the sample was small, we used the Wilcoxin signed rank test to compare platelet values before and after initiation of eltrombopag. A $p$-value $<0.05$ was considered statistically significant. All analyses were performed using SAS v.9.0 (SAS Institute, Cary, NC).

\section{Results}

\section{Study sample}

We identified 51,150 patients with a qualifying predisposing condition, sITP diagnosis, and enrollment in the EHR for at least 3 months before and 6 months after the sITP diagnosis date. After exclusion criteria were applied, there were 
Fig. 2 Sample selection and attrition process for identification of eligible patients. sITP, secondary immune thrombocytopenia. *Other exclusion criteria were multiple identification numbers, missing demographic data, or eltrombopag use prior to sITP diagnosis

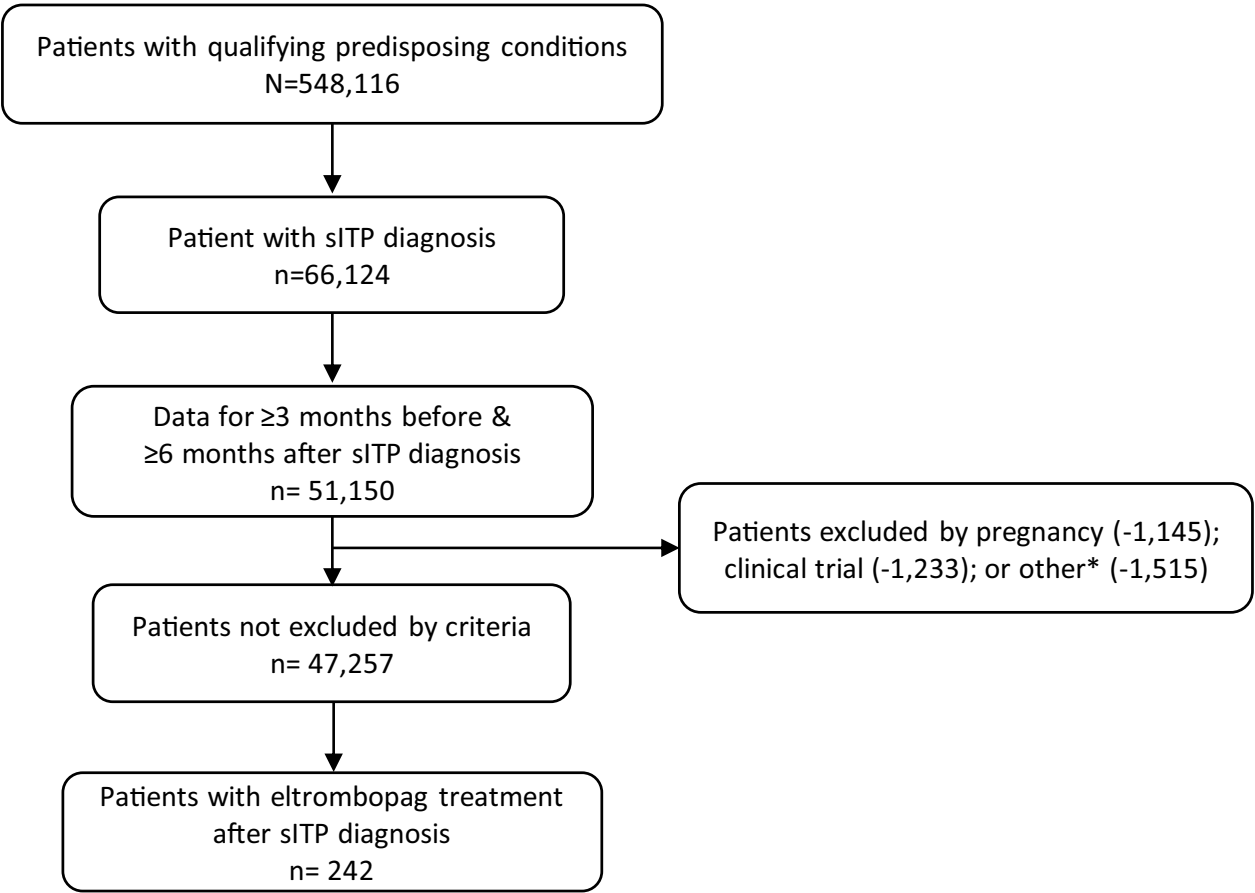

47,257 patients, of whom 242 were prescribed eltrombopag and comprised our study population (Fig. 2).

The average age of patients was 52.5 years, and $50.8 \%$ were female (Table 1). Continuous clinical activity in the EHR database was evident for a mean (SD) 55.5 (32.3) months before and 48.3 (27.1) months after the sITP identification date. The most frequently observed predisposing conditions were HCV, SLE, CLL/SLL, APS, and Evans syndrome.

\section{Treatment patterns}

Eltrombopag therapy began a mean (SD) of 1.1 (4.2) months following the sITP diagnosis date (Table 2). The majority $(n=202 ; 83.5 \%)$ of patients were treated with eltrombopag monotherapy; the remainder were treated with eltrombopag in combination with one or more additional ITP therapies. The average eltrombopag therapy duration was 6.1 months. The therapy ended for $146(60.3 \%)$ patients due to discontinuation of eltrombopag, $45(18.6 \%)$ patients due to a change in treatment, 47 (19.4\%) patients due to end of activity in the EHR or end of the study period, and 4 (1.7\%) patients due to death.

Among the 146 patients who discontinued eltrombopag, 105 patients stopped all therapy and entered a treatment-free period, which was observed through the available follow-up period. The mean (SD) length of the treatment-free period was 3.3 (3.4) months. Among the 86 patients who discontinued eltrombopag and had at least 12 months of follow-up available after the sITP identification date, the mean (SD) treatment-free period was 9.9 (2.6) months.

\section{Platelet response}

Among the 242 patients, 166 had at least one platelet count in the 14 days prior to initiation of eltrombopag. For this set of 166 patients, the mean (SD; [median, minimum, maximum]) platelet count rose significantly from $45,000 / \mathrm{uL}$ $(40,000 / \mathrm{uL}[33,000 / \mathrm{uL}, 3500 / \mathrm{uL}, 251,000 / \mathrm{uL}])$ prior to starting eltrombopag to $76,000 / \mathrm{uL}(70,000 / \mathrm{uL}[52,000 / \mathrm{uL}, 3000$ $/ \mathrm{uL}, 375,000 / \mathrm{uL})$ during eltrombopag therapy $(p<0.0001)$. The mean (SD) number of platelet counts within 14 days prior to eltrombopag initiation was 2.95 (2.78), and during eltrombopag treatment was 16.89 (16.24). Among the entire sample of 242 patients, $197(81.4 \%)$ reached a first response level of $\geq 30,000 / \mu \mathrm{L}$ at a mean of 0.70 months; $170(70.2 \%)$ reached a second response level of $\geq 50,000 / \mu \mathrm{L}$ at a mean of 0.95 months; and 114 patients $(47.1 \%)$ achieved a complete response of $>100,000 / \mu \mathrm{L}$ at a mean of 1.43 months after initiation of eltrombopag (Fig. 3). Mean (SD) platelet counts at 1 month, 3 months, and 6 months following initiation of eltrombopag were $62,000 / \mu \mathrm{L}(56,000), 79,000 / \mu \mathrm{L}(78,000)$, and $83,000 / \mu \mathrm{L}(82,000)$, respectively.

\section{Thrombotic and bleeding events}

Among the 242 patients, a total of 38 patients had $\geq 1$ thrombotic event during the baseline period (Table 3 ). Deep vein thrombosis and pulmonary embolism were the most common. During the eltrombopag treatment period, 19 patients had thrombotic events, most commonly deep vein thrombosis. The mean (SD) number of events per patient was 
Table 1 Patient characteristics

$N=242$

\begin{tabular}{|c|c|}
\hline \multicolumn{2}{|l|}{ Age (continuous), years } \\
\hline Mean (SD) & $52.5(18.0)$ \\
\hline Gender, female, $n(\%)$ & $123(50.8)$ \\
\hline \multicolumn{2}{|l|}{ Insurance type, $n(\%)$} \\
\hline Commercial & $70(28.9)$ \\
\hline Medicaid & $43(17.8)$ \\
\hline Medicare & $53(21.9)$ \\
\hline Commercial/Medicaid & $8(3.3)$ \\
\hline Commercial/Medicare & $19(7.9)$ \\
\hline Medicare/Medicaid & $8(3.3)$ \\
\hline Commercial/Medicare/Medicaid & $2(0.8)$ \\
\hline Invalid, missing, unknown, other & $16(6.6)$ \\
\hline Uninsured & $23(9.5)$ \\
\hline \multicolumn{2}{|l|}{ Race, $n(\%)$} \\
\hline Asian & $3(1.2)$ \\
\hline Black or African American & $36(14.9)$ \\
\hline White or Caucasian & $186(76.9)$ \\
\hline Unknown/other & $17(7.0)$ \\
\hline \multicolumn{2}{|l|}{ Ethnicity, $n(\%)$} \\
\hline Hispanic, Latino, or Spanish & $24(9.9)$ \\
\hline Not Hispanic, Latino, or Spanish & $210(86.8)$ \\
\hline Unknown/other & $8(3.3)$ \\
\hline \multicolumn{2}{|l|}{ Charlson Comorbidity Index score } \\
\hline Mean (SD) & $2.31(1.97)$ \\
\hline \multicolumn{2}{|l|}{ Underlying qualifying conditions, $* n(\%)$} \\
\hline Hepatitis C & $108(44.6)$ \\
\hline SLE & $44(18.2)$ \\
\hline CLL or SLL & $37(15.3)$ \\
\hline APS & $26(10.7)$ \\
\hline Evans syndrome & $19(7.9)$ \\
\hline CVID & $12(5.0)$ \\
\hline HIV & $12(5.0)$ \\
\hline Selective IgA deficiency & $7(2.9)$ \\
\hline Autoimmune lymphoproliferative disorder & $2(0.8)$ \\
\hline
\end{tabular}

$A L P S$, autoimmune lymphoproliferative syndrome; $A P S$, antiphospholipid syndrome; $C L L$, chronic lymphocytic leukemia; $C V I D$, common variable immune deficiency; $H C V$, hepatitis $\mathrm{C}$ virus; $H I V$, human immunodeficiency virus; $S D$, standard deviation; $S L E$, systemic lupus erythematosus; $S L L$, small lymphocytic lymphoma

*Percentages do not add to $100 \%$ because patients may have had more than one condition

$0.16(0.46)$ before treatment and $0.08(0.16)$ after the start of eltrombopag $(p=0.027)$. Only for pulmonary embolism were the proportions of patients significantly different with fewer events during the eltrombopag treatment period ( $3.72 \%$ vs. $0.41 \%, p=0.012$ ). Among all patients, $32.2 \%$ had one or more bleeding events in the 6 months before, and $27.7 \%$ of patients had one or more bleeding events in the 6 months after the start of eltrombopag treatment $(p=0.628)$.

\section{Discussion}

Eltrombopag has been demonstrated to be effective and welltolerated in the treatment of primary ITP in clinical trials and real-world studies. [14, 18, 19] Whether the efficacy and safety of eltrombopag in primary ITP is applicable to patients with SITP is uncertain. We conducted a real-world study of eltrombopag treatment among 242 patients with sITP using EHR data. To our knowledge, this is the largest 
Table 2 Treatment pattern data

\begin{tabular}{ll}
\hline & $N=242$ \\
\hline Time from sITP diagnosis to eltrombopag treatment, months, mean (SD) & $1.1(4.2)$ \\
Duration of eltrombopag treatment, months, mean (SD) & $6.1(6.9)$ \\
Patients who received eltrombopag monotherapy, $n(\%)$ & $202(83.5)$ \\
Patients who received eltrombopag in combination with additional ITP therapy, $n(\%)$ & $40(16.5)$ \\
Reason for the end of observed eltrombopag treatment period, $n(\%)$ & $146(60.3)$ \\
$\quad$ Discontinuation & $45(18.6)$ \\
Add-on or switch & $47(19.4)$ \\
$\quad$ End of activity in EHR database or end of the study period & $4(1.7)$ \\
$\quad$ Death & $105(43.4)$ \\
Individuals who discontinued* eltrombopag treatment, and entered a treatment-free period ${ }^{* *}$ & \\
during available follow-up, $n$ (\%) & $3.3(3.4)$ \\
Observed length of treatment-free period, months, mean (SD) & $84(34.7)$ \\
Individuals with another line of therapy after eltrombopag, $n(\%)$ & $5.7(10.3)$ \\
Time from end of eltrombopag treatment to start of subsequent line, months, mean (SD)
\end{tabular}

SITP, secondary immune thrombocytopenia; $S D$, standard deviation; $E H R$, electronic health record

*Indicates the observed eltrombopag treatment period did not end (was not censored) because of death, end date of study, absence from database, or switch/add-on of another ITP therapy. The end of treatment period would only have been due to a discontinuation of the medication

** A "treatment-free period" indicates that the patient had completed eltrombopag treatment and was receiving neither another secondary ITP treatment, nor any rescue medications (systemic corticosteroids, IVIG, or anti-D)

Fig. 3 Time to threshold platelet count. Size of circles represent the proportion of the entire sample $(81 \%, 70 \%$, and $41 \%$ ) which reached a given platelet count threshold (on the $y$-axis). The mean number of months to achieve that threshold is shown on the $x$-axis

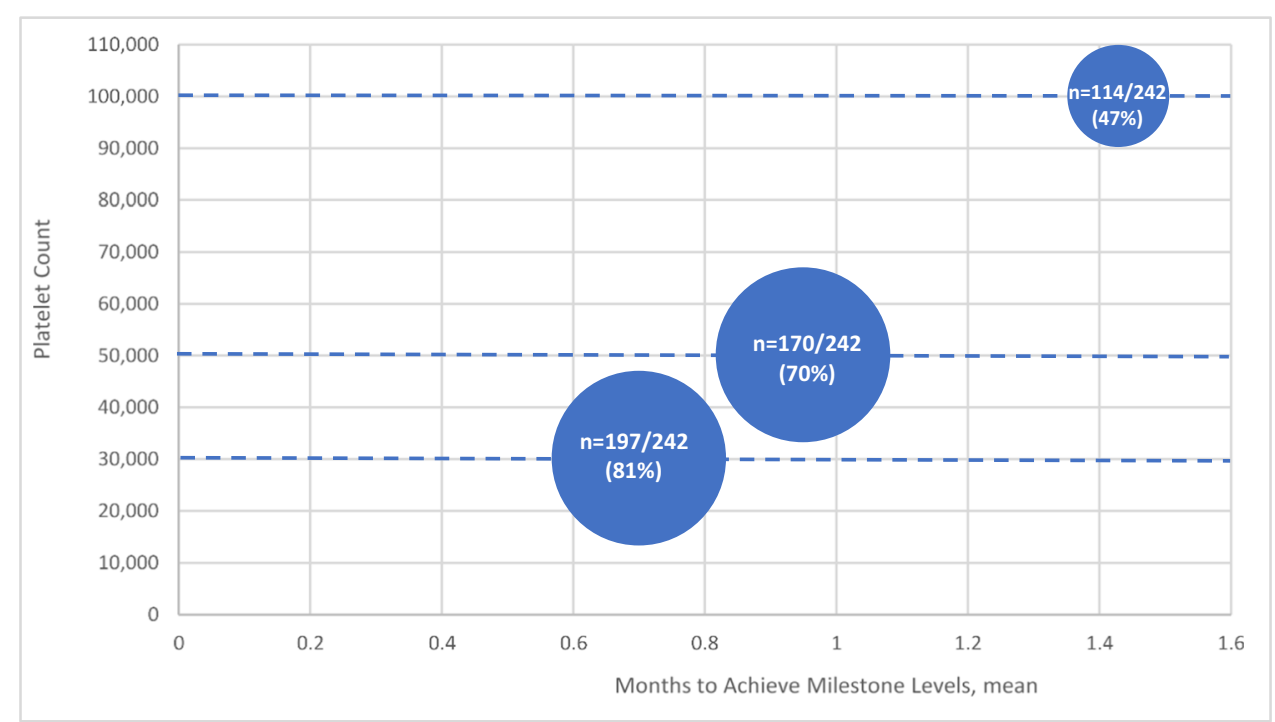

study of a TPO-RA for the treatment of sITP. As with primary ITP, we found that eltrombopag in patients with sITP was associated with improvement in the platelet count and the potential for a subsequent treatment-free period.

The primary goal of treatment with eltrombopag in ITP is an improvement in platelet count and a reduced risk of bleeding events. In this study, the mean (SD) platelet count increased from a pre-treatment level of 45,000/uL $(40,000 /$ $\mathrm{uL})$ to $76,000 / \mathrm{uL}(70,000 / \mathrm{uL})$ during the treatment period $(p<0.0001)$. The majority of patients $(70 \%)$ reached a second-level platelet response of $\geq 50,000 / \mu \mathrm{L}$ in a mean time of
1.0 month and $47 \%$ achieved a complete platelet response ( $>100,000 / \mu \mathrm{L})$ at mean of 1.4 months. By comparison, in a real-world sample of 87 Spanish patients with sITP, 35\% of patients reached a complete response, but their starting median platelet count $(14,000 / \mu \mathrm{L})$ was lower than in our study. [16] Although differences in patient population and outcome definitions limit the ability to compare our findings with clinical trials of eltrombopag in primary ITP, the response rates we observed do not appear to be inferior to those reported in such trials. For example, Bussel and colleagues reported achievement of a platelet count of 50,000/ 
Table 3 Thrombotic and bleeding events during study period, $n=242$

\begin{tabular}{|c|c|c|c|}
\hline & $\begin{array}{l}\text { 6-month baseline period } \\
\text { before eltrombopag }\end{array}$ & $\begin{array}{l}\text { Eltrombopag treat- } \\
\text { ment period* } *\end{array}$ & $p$-values \\
\hline Thrombotic events, mean (SD) per patient & $0.16(0.46)$ & $0.08(0.31)$ & 0.027 \\
\hline \multicolumn{4}{|l|}{ Patients with specific events, $n(\%)$} \\
\hline Thrombotic stroke & $6(2.48)$ & $4(1.65)$ & 0.528 \\
\hline Transient ischemic attack & $4(1.65)$ & $2(0.83)$ & 0.416 \\
\hline Myocardial infarction & $4(1.65)$ & $3(1.24)$ & 0.706 \\
\hline Deep vein thrombosis & $15(6.20)$ & $9(3.72)$ & 0.222 \\
\hline Pulmonary embolism & $9(3.72)$ & $1(0.41)$ & 0.012 \\
\hline $\begin{array}{l}\text { Bleeding and hemorrhage events, } n(\%) \text { of } \\
\text { patients with } \geq 1 \text { event }\end{array}$ & $78(32.2)$ & $67(27.7)$ & 0.628 \\
\hline \multicolumn{4}{|l|}{$S D$, standard deviation } \\
\hline \multicolumn{4}{|c|}{$\begin{array}{l}\text { * These are new events not occurring during the baseline period; an event was not counted in both time } \\
\text { periods }\end{array}$} \\
\hline
\end{tabular}

$\mu \mathrm{L}$ or higher among $50 \%$ of patients receiving eltrombopag within 0.5 months. [14] In the phase III RAISE trial, 79\% of eltrombopag-treated patients achieved this platelet count threshold. [18].

Notable results were observed in this study regarding durability of response after discontinuation of eltrombopag treatment. After discontinuing eltrombopag, $43 \%$ of patients entered a treatment-free period for a mean of 3.3 months. Among those with at least 12 months of follow-up, the mean treatment-free period was 9.9 months. These findings align with observations in primary ITP, which show that approximately one-third of patients on eltrombopag are ultimately able to sustain a durable platelet response off all treatment. [20-22].

Bleeding events in the 6 months prior to treatment with eltrombopag were not significantly reduced in the 6 months after the start of treatment ( $32 \%$ vs. $28 \%, p=0.628)$. This may be because the observation period was of insufficient length to detect differences in bleeding or because platelet counts, while lower in the baseline period, were generally in a hemostatic range. Whether treatment with TPO-RAs increases thrombotic risk in patients with ITP remains a matter of controversy. [23] Reassuringly, compared with the 6-month baseline period, the mean number of thromboembolic events per patient was lower in the 6 months after initiation of eltrombopag ( 0.16 vs. $0.08, p=0.027)$.

\section{Limitations}

As in all analyses using EHR data, certain limitations should be considered when interpreting our findings, including (1) the possibility of coding errors in the data, (2) a code for a disease does not guarantee accurate diagnosis, and (3) prescription orders do not confirm accurate or complete filling or administration of a medication. Some findings could only be identified by ICD codes, without additional descriptors; for example, bleeding events did not include data on type or grade of bleeding. The study design limits the ability to determine risk of developing thromboembolism or other events as associated with sITP with unadjusted p-values. Furthermore, although we had initially planned to conduct subgroup analyses based on predisposing condition, we were unable to meet this objective due to small sample sizes for the various conditions. Thus, while our results may apply to sITP patients with predisposing conditions that were wellrepresented in our cohort such as HCV, SLE, and CLL/SLL, they may not apply to predisposing conditions that were underrepresented in our study. Further research is needed to determine the effectiveness and safety of eltrombopag in patients with sITP and specific predisposing conditions. Guidelines state that most adults with ITP do not warrant treatment unless the platelet count is less than $30,000 / \mathrm{uL}^{12}$ The mean pre-treatment platelet count $(45,000 / \mathrm{uL})$ in our cohort was above this threshold, suggesting that at least some eltrombopag-treated patients may not have required therapy. Finally, we did not capture information on treatment for predisposing conditions (e.g., antiviral therapy for $\mathrm{HCV}$ ) and how such treatment may have affected the platelet count.

\section{Conclusions}

Our results suggest that, among patients with sITP, eltrombopag shows similar effectiveness in improving platelet counts, compared with patients with primary ITP. In addition, as with primary ITP, a treatment-free period is possible for a substantial minority of patients. Prospective clinical studies specifically designed to evaluate eltrombopag for the treatment of sITP are needed.

Supplementary Information The online version contains supplementary material available at https://doi.org/10.1007/s00277-021-04637-2. 
Acknowledgements Medical writing assistance was provided by Caroline Jennermann, MS, of Optum HEOR, supported by Novartis Pharmaceuticals Corporation.

Author contribution PP, AL, LSL, LG, LL, SN, and AC made significant contributions to conception and design and/or analysis and interpretations of data; were involved in the drafting and critical revision of the manuscript; and provided final approval for publication. All authors are accountable for accuracy and integrity of the work.

Funding This study was funded by Novartis Pharmaceutical Corporation.

Data availability Use of the proprietary data obtained from the Optum Research Database requires strictest data security and privacy protocols and a restrictive license agreement. Thus, data used to generate the results presented are cannot be disclosed publicly.

\section{Declarations}

Ethics approval Data obtained within this study were accessed in manners compliant with the Health Insurance Portability and Accountability Act. Only de-identified claims were accessed; as such, institutional review and approval were neither sought nor obtained.

Conflict of interest The authors declare no competing interests.

Open Access This article is licensed under a Creative Commons Attribution 4.0 International License, which permits use, sharing, adaptation, distribution and reproduction in any medium or format, as long as you give appropriate credit to the original author(s) and the source, provide a link to the Creative Commons licence, and indicate if changes were made. The images or other third party material in this article are included in the article's Creative Commons licence, unless indicated otherwise in a credit line to the material. If material is not included in the article's Creative Commons licence and your intended use is not permitted by statutory regulation or exceeds the permitted use, you will need to obtain permission directly from the copyright holder. To view a copy of this licence, visit http://creativecommons.org/licenses/by/4.0/.

\section{References}

1. Nugent D, McMillan R, Nichol JL, Slichter SJ (2009) Pathogenesis of chronic immune thrombocytopenia: increased platelet destruction and/or decreased platelet production. Br J Haematol 146(6):585596. https://doi.org/10.1111/j.1365-2141.2009.07717.x

2. Cines DB, Bussel JB, Liebman HA, Luning Prak ET (2009) The ITP syndrome: pathogenic and clinical diversity. Blood 113:6511-6521. https://doi.org/10.1182/blood-2009-01-129155

3. Cines DB, Liebman H, Stasi R (2009) Pathobiology of secondary immune thrombocytopenia. Semin Hematol 46:S2-S14. https://doi. org/10.1053/j.seminhematol.2008.12.005

4. Arnal C, Piette JC, Léone J, Taillan B, Hachulla E, Roudot-Thoraval $F$ et al (2002) Treatment of severe immune thrombocytopenia associated with systemic lupus erythematosus: 59 cases. J Rheumatol 29(1):75-83

5. Kistanguri G, McCrae KR (2013) Immune thrombocytopenia. Hematol Oncol Clin North Am 27(3):495-520. https://doi.org/10. 1016/j.hoc.2013.03.001

6. Teachey DT (2012) New advances in the diagnosis and treatment of autoimmune lymphoproliferative syndrome. Curr Opin Pediatr 24(1):1-8. https://doi.org/10.1097/MOP.0b013e32834ea739
7. Rajan SK, Espina BM, Liebman HA (2005) Hepatitis C virus-related thrombocytopenia: clinical and laboratory characteristics compared with chronic immune thrombocytopenic purpura. $\mathrm{Br} \mathrm{J}$ Haematol 129(6):818-824. https://doi.org/10.1111/j.1365-2141.2005.05542.x

8. Zhang W, Nardi MA, Borkowsky W, Li Z, Karpatkin S (2009) Role of molecular mimicry of hepatitis $\mathrm{C}$ virus protein with platelet GPIIIa in hepatitis C-related immunologic thrombocytopenia. Blood 113(17):4086-4093. https://doi.org/10.1182/blood-2008-09-181073

9. Li Z, Nardi MA, Karpatkin S (2005) Role of molecular mimicry to HIV-1 peptides in HIV-1 related immunologic thrombocytopenia. Blood 106:572-576. https://doi.org/10.1182/blood-2005-01-0243

10. Stasi R, Sarpatwari A, Segal JB, Osborn J, Evangelista ML, Cooper $\mathrm{N}$ et al (2009) Effects of eradication of Helicobacter pylori infection in patients with immune thrombocytopenic purpura: a systematic review. Blood 113(6):1231-1240. https://doi.org/10.1182/ blood-2008-07-167155

11. Liebman HA (2009) Recognizing and treating secondary immune thrombocytopenic purpura associated with lymphoproliferative disorders. Semin Hematol 46(1 Suppl 2):S33-S36. https://doi.org/10. 1053/j.seminhematol.2008.12.004

12. Neunert C, Terrell DR, Arnold DM, Buchanan G, Cines DB, Cooper $\mathrm{N}$ et al (2019) American Society of Hematology 2019 guidelines for immune thrombocytopenia. Blood Adv 3(23):3829-3866. https:// doi.org/10.1182/bloodadvances.2019000966

13. Jenkins JM, Williams D, Deng Y, Uhl J, Kitchen V, Collins D et al (2007) Phase 1 clinical study of eltrombopag, an oral, nonpeptide thrombopoietin receptor agonist. Blood 109(11):4739-4741. https:// doi.org/10.1182/blood-2006-11-057968

14. Bussel JB, Cheng G, Saleh MN et al (2007) Eltrombopag for the treatment of chronic idiopathic thrombocytopenic purpura. NEJM 357:2237-2247. https://doi.org/10.1056/NEJMoa073275

15. Erickson-Miller CL, Delorme E, Tian SS, Hopson CB, Landis AJ, Valoret EI et al (2009) Preclinical activity of eltrombopag (SB497115), an oral, non-peptide thrombopoietin receptor agonist. Stem Cells 27(2):424-430. https://doi.org/10.1634/stemcells.2008-0366

16. González-López TJ, Alvarez-Román MT, Pascual C, SánchezGonzález B, Fernández-Fuentes F, Pérez-Rus G et al (2017) Use of eltrombopag for secondary immune thrombocytopenia in clinical practice. Br J Haematol 178(6):959-970. https://doi.org/10.1111/ bjh.14788 (Epub 2017 Jun 1)

17. Quan H, Li B, Couris CM, Fushimi K, Graham P, Hider P et al (2011) Updating and validating the Charlson comorbidity index and score for risk adjustment in hospital discharge abstracts using data from 6 countries. Am J Epidemiol 173(6):676-682. https://doi.org/ 10.1093/aje/kwq433 (Epub 2011 Feb 17)

18. Cheng G, Saleh MN, Marcher C, Vasey S, Mayer B, Aivado M et al (2011) Eltrombopag for management of chronic immune thrombocytopenia (RAISE): a 6-month, randomized phase 3 study. Lancet 377:393-402. https://doi.org/10.1016/S0140-6736(10)60959-2

19. Khelif A, Saleh MN, Salama A, Portella MDSO, Duh MS, Ivanova J et al (2019) Changes in health-related quality of life with long-term eltrombopag treatment in adults with persistent/chronic immune thrombocytopenia: findings from the EXTEND study. Am J Hematol 94(2):200-208. https://doi.org/10.1002/ajh.25348

20. Lal LS, Said Q, Andrade K, Cuker A. Second-line treatments and outcomes for immune thrombocytopenia: a retrospective study with electronic health records. Res Practice Thromb Haemost. E-pub 2020 Sep 11. https://doi.org/10.1002/rth2.12423. Available at https://onlinelibrary.wiley.com/doi/epdf/https://doi.org/10.1002/ rth2.12423

21. Leven E, Miller A, Boulad N, Haider A, Bussel JB (2012) Successful discontinuation of eltrombopag treatment in patients with chronic ITP. Blood 120(21):1085. https://doi.org/10.1182/blood.V120.21. 1085.1085

22. Mahevas M, Fain O, Ebbo M, Roudot-Thoraval F, Limal N, Khellaf $\mathrm{M}$ et al (2014) The temporary use of thrombopoietin-receptor 
agonists may induce a prolonged remission in adult chronic immune thrombocytopenia. Results of a French observational study. Br J Haematol 165:865-869. https://doi.org/10.1111/bjh.12888

23. Catalá-López F, Corrales I, de la Fuente-Honrubia C, González-Bermejo D, Martin-Serrano G, Montero D et al (2015) Risk of thromboembolism with thrombopoietin receptor agonists in adult patients with thrombocytopenia: systematic review and meta-analysis of randomized controlled trials. Med Clin (Barc) 145(12):511-519. https://doi.org/10.1016/j.medcli.2015.03.014

Publisher's note Springer Nature remains neutral with regard to jurisdictional claims in published maps and institutional affiliations. 